\title{
REVIEW
}

\section{Adenoid cystic carcinoma. An indolent but aggressive tumour. Part B: treatment and prognosis}

\author{
Carcinoma adenoide cistico. Un tumore indolente ma aggressivo. \\ Parte B: trattamento e prognosi
}

\author{
Giulio Cantù \\ Former Director of Otorhinolaryngology and Cranio-Maxillo-Facial Unit, Fondazione I.R.C.C.S. Istituto Nazionale dei Tumori, Milano, Italy
}

\begin{abstract}
SUMMARY
The purpose of this review is to analyse the very large number of studies (sometimes contradictory) on adenoid cystic carcinoma (ACC). This second part provides a critical analysis of various treatment described in the literature. Anywhere the primary tumour is located, the most common treatment for ACC is complete surgical resection, with or without postoperative radiotherapy (PORT), while conventional photon and/or electron radiotherapy alone and chemotherapy are commonly used in unresectable or metastatic disease. Fast neutron radiotherapy was used in the past with good local results, but the risk of late effects was high and tended to increase over time. Modern carbon-ion radiotherapy seems to be a valid option in selected cases. The quite universally accepted poor prognostic factors are advanced stage, perineural and intraneural invasion, involved margins, and initial presence or later development of neck metastases. The impact of histologic grade on prognosis is controversial. Owing to the long natural history of ACC, the follow-up for patients must be at least 10 years long.
\end{abstract}

KEY WORDS: adenoid cystic carcinoma, salivary gland tumors, head and neck cancer, prognostic factors

\section{RIASSUNTO}

Il proposito di questa review è quello di analizzare il grande numero di studi (talvolta contradittori) sul carcinoma adenoide cistico. Questa seconda parte presenta una analisi critica dei vari trattamenti descritti in letteratura. Ovunque il tumore primitivo sia localizzato il trattamento più indicato è una resezione radicale con o senza radioterapia postoperatoria. La radioterapia convenzionale con fotoni elo elettroni e la chemioterapia sono comunemente riservate ai casi inoperabili o metastatici. La radioterapia con neutroni è stata ampiamente utilizzata in passato con buoni risultati locali, ma il rischio di effetti collaterali tardivi si è dimostrato alto e con tendenza ad aumentare nel tempo. Il moderno trattamento con ioni carbonio si sta dimostrando una valida alternativa in casi selezionati. I fattori prognostici negativi quasi universalmente accettati sono lo stadio avanzato, l'invasione perineurale e intraneurale, i margini positivi e le metastasi linfonodali alla presentazione o successive. Il valore prognostico del grading istologico è controverso. Stante la lunga storia naturale del carcinoma adenoide cistico il follow-up dei pazienti deve essere almeno di 10 anni.

PAROLE CHIAVE: carcinoma adenoide cistico, tumori ghiandole salivari, carcinoma testa e collo, fattori prognostici

\section{Treatment}

\section{Surgery}

Anywhere the primary tumour is located, the most common treatment for adenoid cystic carcinoma (ACC) is complete surgical resection. For the breast, surgery is either a lumpectomy or a simple, radical or modified radical mas-
Received: January 12, 2021

Accepted: May 3, 2021

\author{
Correspondence \\ Giulio Cantù \\ via Milano 36, 20846 Macherio (MB), Italy \\ E-mail: gcantu43@gmail.com
}

Funding

None.

\section{Conflict of interest}

The Author declares no conflict of interest.

\begin{abstract}
How to cite this article: Cantù G. Adenoid cystic carcinoma. An indolent but aggressive tumour. Part B: treatment and prognosis. Acta Otorhinolaryngol Ital 2021;41:296-307. https:// doi.org/10.14639/0392-100X-N1729
\end{abstract}

() Società Italiana di Otorinolaringoiatria e Chirurgia Cervico-Facciale

\section{(c) (1) $(9)$}

This is an open access article distributed in accordance with the CC-BY-NC-ND (Creative Commons Attribution-NonCommercial-NoDerivatives 4.0 International) license. The article can be used by giving appropriate credit and mentioning the license, but only for non-commercial purposes and only in the original version. For further information: https:// creativecommons.org/licenses/by-nc-nd/4.0/deed.en 
tectomy, with or without adjuvant radiation therapy ${ }^{1,2}$. The mainstay of treatment for ACC of the tracheobronchial tree is surgical resection. When the radical resection (R0) is over risky or may cause mortal complication, the R1 resection (close margins) with adjunctive therapy is acceptable for patients to obtain a promising prognosis ${ }^{3,4}$. The same indications are valid also for the skin ${ }^{5}$ and female genital system ${ }^{6}$.

Surgery is the primary treatment for ACCs arising from major and minor salivary glands of the head and neck. In the National Comprehensive Cancer Network (NCCN) Guidelines $2019^{7}$ one may find this: "The major therapeutic approach for salivary gland tumors is adequate and appropriate surgical resection. Surgical intervention requires careful planning and execution, particularly in parotid tumour surgery because the facial nerve is in the gland". Certainly, the two adjectives (adequate and appropriate) have been carefully chosen because the radical resection of a parotid tumour according to the usual rules (free margins $\geq 5 \mathrm{~mm}$ ) is often impossible without the sacrifice of some branches of the facial nerve. Owing to the complex branching and connections of the facial nerve within the parotid, a quite small ACC of the superficial lobe of the gland can often approach or come into contact with a branch of the nerve. A real radical resection would entail the sacrifice of this branch. However, the facial nerve is aesthetically and functionally so important that almost all authors agree with the preservation of the nerve when it is possible to dissect it from the tumour. "The facial nerve should be sacrificed (and possibly repaired) if there is preoperative nerve involvement with palsy or if there is direct invasion of the tumour into the nerve where the tumour cannot be separated from the nerve" ${ }^{7}$. The aforesaid surgical behaviour is a compromise between one of the dogmas of oncologic surgery (clean margins) and aesthetic and functional results. Most published studies on head and neck ACC do not report margins status. I found only three studies reporting this datum ${ }^{8-10}$. Garden et al. ${ }^{8}$ found that $83 / 198$ patients (42\%) had microscopic positive margins and an additional $55(28 \%)$ had close or uncertain margins. In the study by Erovic et al. ${ }^{9}$, positive surgical margins (i.e. tumour extending to the inked margin of specimen) were identified in $38.9 \%$ of patients who underwent parotidectomy for malignant tumours and in 12/20 (60\%) patients with ACC. In the study by Lee et al. ${ }^{10}$ there was a $50.82 \%$ rate of closed or positive surgical margins.

In the light of the aforesaid uncertain radicality, the debate between superficial or total parotidectomy is rather pointless. Nevertheless, in the past century some authors advocated total parotidectomy for all benign and malignant tumours ${ }^{11}$, and radical parotidectomy with facial nerve sac- rifice also in patients without preoperative facial weakness and $\mathrm{T} 2$ tumour ${ }^{12}$. However, beyond these extremisms, an Italian multicentre study demonstrated that total parotidectomy with or without facial nerve sacrifice was performed in 79\% of patients with malignant tumours between 1993 and $2003{ }^{13}$. Conservative total parotidectomy was the most common operation in the study by Boahene et al. ${ }^{14}$ Also in the United Kingdom National Multidisciplinary Guidelines one can find the following sentence: "For small, low-grade superficial tumours a partial parotidectomy may suffice but otherwise a total conservative parotidectomy is advocated" ${ }^{15}$. One must wonder which improvement of radicality may give the resection of few uninvolved glandular acini of the deep lobe after having dissected with difficulty the tumour from some branches of the facial nerve. Certainly, this resection implies a greater manipulation of the nerve and a higher incidence of facial nerve dysfunction during the first postoperative period than superficial parotidectomy ${ }^{16}$.

The resection of an ACC of the submandibular gland is apparently less problematic, but the surgeon must avoid some possible pitfalls. First of all, the gland is surrounded by several lymph nodes which may be involved by the ACC. Allen et al. ${ }^{17}$ demonstrated that "when lymph node involvement does occur, it does not result from embolic lymph node metastasis; rather, a direct invasion of the lymph node from tumour in the perinodal soft tissue occurs". In a following study, Bosch et al. ${ }^{18}$ demonstrated that there was a higher incidence of neck metastases in ACC of the submandibular gland in comparison with the parotid gland and it was due to direct extension of the tumour from the gland to the adjacent nodes rather than by a classic embolic metastasis. For this reason, Batsakis wrote: "In surgical procedures it is best to remove the entire nodular and glandular contents of the submandibular compartment rather than perform partial excision of the gland" ${ }^{19}$. Secondly, it is almost always possible to preserved the hypoglossal nerve because of its deep location in the submandibular triangle, but the lingual nerve is often approached or involved by the tumour because it crosses the anterior portion of the gland, which lies along its duct. Batsakis ${ }^{19}$ reported a particularly high rate of local recurrence of ACC of the submandibular gland.

Also for ACCs of paranasal sinuses surgical resection (when possible) with postoperative radiotherapy is the best treatment. The surgical procedure most commonly performed is maxillectomy with varying degrees of resection of the ethmoid sinus; the resection must be extended to the orbit and to the skull base when it is necessary. Unfortunately, many patients present with very advanced tumours, so making difficult to achieve clean margins. In the series by Michel et al. ${ }^{20} 65 \%$ of operated patients had positive 
surgical margins on histological examination of the operative specimen. The same rate of positive margins is reported by Miller et al. ${ }^{21}$. Cantù et al. ${ }^{22}$ achieved clean margins in $56.5 \%$ in a series of patients with very large maxillary ACC invading the middle cranial fossa (T4b).

The surgical approach for the resection of an ACC of the oral cavity depends on the subsite of the tumour. The hard palate is the most commonly involved subsite in almost all published series ${ }^{23-26}$. Owing to the infiltrative submucosal grown of ACC, it can infiltrate the underlying bone and invade the sinonasal cavities. The resection of the tumour may require a subtotal or total maxillectomy.

The most common site of origin of ACCs of the oropharynx is the base of tongue. For rare small tumours it may be possible a transoral resection or, nowadays, a transoral robotic resection. On the contrary, a pull-through or a mandibulotomy approach is required for the frequent large tumours involving both the base and the mobile tongue. In these cases a reconstruction with pedicled or microvascular free flaps is mandatory.

Partial laryngectomy is rarely possible for the resection of ACCs of the larynx. Unfortunately, total laryngectomy is the most frequent surgical treatment.

Considering that the surgical treatment of the neck is indicated when there is clinical evidence of regional metastasis or when the resection of the primary tumour implies a trans-cervical approach, the management of a clinically node-negative neck (N0) in this context remains controversial, mainly for malignancies of the parotid gland. Should an elective neck dissection (END) be performed or is a wait and watch policy safe and adequate? This question has been a contentious issue spanning five decades. In fact, Eneroth et al advocate radical neck dissection for all tumours, even without clinically involved lymph nodes, except for low grade MEC ${ }^{27}$. On the contrary, some other authors ${ }^{19,28}$ demonstrated that only the high-grade adenocarcinomas, MEC, and carcinomas ex pleomorphic adenoma manifest a significant lymphatic spread. The question is not yet solved. Also in more recent years, many authors advocate END only for high stage (T3/T4) and/or high grade tumours (salivary duct carcinoma, adenocarcinoma, and high grade MEC) ${ }^{10,29-31}$. Almost always ACC is left in an doubtful position.

However, there is an unsolved problem: while it is easy to know preoperatively the stage of the tumour, it is often impossible to know its grade and, sometimes, even its histology. As above mentioned, FNAC has a low diagnostic potential for tumour typing and grading. Zbären et al. ${ }^{32}$ found that in their series the tumour typing and grading by FNAC was accurate in 50\% and 45\%, respectively. Moreover, even with intraoperative frozen section tumour typing and grad- ing was correct in $68 \%$ and $71 \%$ of the cases, respectively. Therefore, they settled the question suggesting "a routine END in all primary carcinomas of the parotid glands. The neck dissection can easily be incorporated into the surgical approach with practically no additional morbidity and only a slight increase in operative time" ${ }^{32}$. I believe that the spinal accessory nerve does not enjoy this statement. Other authors demonstrated that the rate of regional metastases is quite low and does not justify a systematic elective neck dissection ${ }^{33}$. A review of 18 studies involving 2993 patients demonstrated that ACCs of minor salivary gland have a higher cervical lymph node metastases rate in comparison with major salivary glands. Therefore, the authors suggested that END might be applied only to ACC of minor salivary glands ${ }^{34}$. On the contrary, a review on the management of minor salivary gland carcinoma concluded that the occult metastasis rate, as evidenced by the appearance of metastasis in the untreated N0 neck, is too low to justify END, except in patients with high-grade cancers such as high-grade MEC ${ }^{35}$. Another review concluded that only in some oral and oropharyngeal locations does occult nodal involvement approach $>20 \%$, reaching the level normally used to justify END ${ }^{36}$.

The peculiarity of this controversy is that all authors report quite the same rate of neck node metastases in $\mathrm{cN} 0$ neck (between 13\% and 20\%). Different opinion lies in considering high or low these rates. Moreover, some studies demonstrated that every type of neck dissection implies possible iatrogenic damage (mainly to the spinal accessory nerve) ${ }^{37-39}$. Therefore, the most important question is: how much END in cN0 patients can improve the overall (OS) and/or disease free survival (DFS)? Unbelievably, almost all authors did not find any difference between patient treated and those observed. "END of cN0 patients does not provide any benefit on event free survival, which suggests that its application on such patients is not necessary" ${ }^{33}$. "There was no significant enhanced survival in the group of patients who underwent END" ${ }^{40}$. "Although END is associated with a prolonged regional recurrence-free period, its influence on final outcome or survival is still controversial" ${ }^{41}$. "In the majority of patients $(65 \%)$, the neck was observed rather than treated electively, with no impact on overall survival. These data support our policy of reserving END only for those histologic diagnoses that carry the highest risk of nodal metastases, as well as for selected patients whose primary tumour resection might be facilitated by lymphadenectomy" ${ }^{42}$. As sometimes happens, one can find controversial conclusions in two analyses of the same series. "Our findings support the consideration of END in patients with ACC of the oral cavity" ${ }^{43}$. "Statistical analysis showed no survival advantage for patients who under- 
went END compared with those who did not" ${ }^{44}$. The real value of END in NO ACC has been stated by the following sentence. "Although END itself did not have beneficial effects on distant metastasis or survival, END can provide valuable staging and prognostic information" ${ }^{10}$.

Fortunately, two studies with large series of patients made a good contribution to settle the question of END for parotid malignancies. Lim et al. ${ }^{45}$, analysing a series of 86 patients with parotid cancer, demonstrated that using intraparotid lymph node metastasis status to predict cervical nodal metastasis resulted in a sensitivity and specificity of $70 \%$ and $90.6 \%$, respectively (positive predictive value of $87.3 \%$ ). However, a recent review on this topic raised the objection that intraparotid lymph node metastasis may not be first echelon lymph nodes for regional spreading in all cases. "It is imaginable that if the tumour is located in the far inferior part of parotid gland, level IIa or IIb lymph node metastasis might regularly occur without intraparotid lymph node metastasis" ${ }^{46}$. The study by Erovic et al. ${ }^{9}$ overcame this objection. In their series of 215 patients with parotid cancer, all patients underwent parotidectomy and resection of the lymph nodes surrounding the inferior lobe (periparotid nodes). These lymph nodes were macroscopically examined and enlarged nodes were sampled and, if frozen section examination confirmed metastases, an appropriate neck dissection was performed. Lateral neck metastases were more common in cases with positive periparotid nodes than in those that did not. In addition, almost half of the patients with a positive periparotid node were staged clinically as being N0. Thus, a decision for END may be made at the time of surgery on identifying a periparotid node and evaluating for metastases on frozen section analysis. Interestingly, periparotid nodal metastases were most commonly noted with salivary duct carcinomas $(61 \%)$. This was followed in frequency by adenocarcinoma (22.7\%), MEC (17.9\%), acinic cell carcinoma (8.2\%), carcinoma ex pleomorphic adenoma (6.7\%), and ACC (3.9\%). Another unsolved question is the appropriate type of neck dissection for parotid malignancies. Apart from the historical treatment with prophylactic radical neck dissection ${ }^{27}$, in more recent years most authors advocate a selective neck dissections for cN0 cases. "Levels II to IV were regularly removed for parotid tumours, levels I to III for submandibular and sublingual tumours, and levels I to IV for minor gland tumors" 29 . "If performed, END should be limited to levels I-III of the ipsilateral neck since occult metastases are exclusively located within these neck regions" ${ }^{41}$. Unfortunately, all these statements are not supported by undisputable proofs. Due to the rarity of parotid malignancies, the data on topography of nodal disease is scarce. Hence, there is no consensus as to which nodal levels should be included in END or extent of therapeutic neck dissection for parotid malignancies.

An interesting study by Chisholm et al. ${ }^{47}$ tried to solve the question. The objective of their study was to ascertain the distribution pattern or topography of cervical nodal metastases from primary parotid carcinomas. They reviewed 474 articles reporting neck metastases and found only 2 studies reporting the topography of nodal disease in $\mathrm{cN} 0$ patients undergoing prophylactic neck dissection ${ }^{48,49}$. The data from these 2 series were combined with their own data to form a virtual series of 66 cases of primary parotid carcinoma with cervical nodal spread. The results demonstrated that the overall distribution of cervical disease in primary parotid carcinoma is diffuse: level I 28\%, level II 59\%, level III 52\%, level IV 38\%, and level V $41 \%$. Moreover, $17 \%$ of patients had single nodes ( $\mathrm{N} 1$ or N2a), levels I and V were only involved in conjunction with other levels, level IV was involved by itself in 2 cases, one patient had level II and IV disease without any involvement in the intervening level III. The authors concluded that these data point away from the use of the often recommended supraomohyoid neck dissection as an oncologically safe procedure in therapeutic END for primary parotid carcinomas, because the diffuse distribution of cervical nodal metastases does not support a high echelon neck dissection or radiotherapy fields limited to the upper chain in the management of cervical nodal disease.

Among frequent, and sometimes late, distant metastases (DM) the most commonly involved site is the lung ${ }^{50,51}$. Moreover, lung metastases are distinct from other sites because they often progress slowly and show symptoms only after a long time, unlike the behaviours of distant metastases in other organs. Lung metastases in ACC are asymptomatic and lung function can be retained for a long period of time ${ }^{52}$. Hence, is their surgical resection worthy? The opinions about this treatment are conflicting. Spiro ${ }^{53}$ in 1997 wrote: "Considering that lung metastases are usually multiple, and prolonged survival without treatment is not unusual, resection of pulmonary metastases may be hard to justify in ACC patients based on the limited experience thus far reported". On the contrary, Locati et al reported a series of 20 patients with lung metastases and concluded that lung metastasectomy provided a prolonged freedom from progression in a high selected subset of patients with ACC (patients with a disease-free interval $\geq 36$ months, $\leq 6$ metastases, and monolateral lung involvement) ${ }^{54}$. A more recent study on 109 patients from the International Registry of Lung Metastases demonstrated that lung metastasectomy should be considered as a therapeutic option to achieve local control of disease when 2 conditions are met: (a) complete surgical resection is feasible and (b) the time 
to pulmonary relapse after primary tumour treatment is greater than 36 months ${ }^{55}$.

\section{Radiotherapy}

Postoperative radiotherapy (PORT) is almost always used for ACC. As far as 1977, Osborn ${ }^{56}$ wrote: "All cases were treated by varying combinations of surgery and irradiation, the former usually preceding the latter though not necessarily of a radical nature in the first instance". Since then, many other authors confirmed this indication. Mendenhall et al. used PORT, regardless of margin status and site of the tumour, in essentially all cases, except for the occasional patient with a grade 1 T1N0 lesion resected with widely negative margins ${ }^{57}$. Other authors concluded that PORT "with a dose of at least $60 \mathrm{~Gy}$ is indicated for patients with T3-4 tumours, incomplete or close resection, bone invasion, perineural invasion, and $\mathrm{pN}(+)$ " ${ }^{58}$. Also the analysis of thousands cases from the SEER by Mahmood et al. demonstrated that PORT is associated with improved survival for high-grade and/or locally advanced malignant major salivary gland tumours ${ }^{59}$. The same conclusion has been drawn by Safdieh et al. analysing as many as 4,068 major salivary glands malignant tumours from the $\mathrm{NCDB}{ }^{60}$. Lee et al. ${ }^{61}$ analysed 1,784 cases of ACC from the NCDB and concluded that PORT for salivary ACC was associated with improved survival even for those with early-stage disease. Moreover, they found that there was no survival benefit for intensity modulated radiotherapy (IMRT) over threedimensional radiation therapy. Garden et al. ${ }^{8}$ demonstrated that patients with positive margins had an improved likelihood of local control with RT doses of 56 Gy or more (88\% vs $40 \%$ ). However, it is worth noting that some of these studies ${ }^{58-60}$ analysed all salivary malignant tumours, and that two studies using national population-based data demonstrated that PORT does not significantly affect patient survival outcomes ${ }^{62,63}$.

Another vexed question is whether and when it appears justified the inclusion of the neck in the fields of radiotherapy. Obviously, all authors agree with PORT on the neck in cases with cervical lymph node metastases, mainly in cases with extracapsular spread ${ }^{64}$. On the contrary, elective neck RT on cN0 neck is more controversial. Authors supporting END underline that negative nodal findings will allow the postoperative radiation field to be limited to the primary site $^{32}$. Other authors advocate performing a neck dissection only in cases of a clinically or radiologically determined presence of lymph node metastases and support the view that radiation therapy is adequate for treating subclinical disease ${ }^{65}$. However, in the series of ACC with a clinically negative neck presented by Mendenhall et al. ${ }^{57}, 33$ patients were observed, and 55 received elective neck RT. The rates of neck control at 5 years in the two groups was quite the same (97\% vs 98\%). A following study by the same centre concluded that elective nodal irradiation should be considered for primary sites located in lymphatic-rich regions, namely the submandibular gland ${ }^{66}$.

Mendenhall et al. ${ }^{57}$ investigated the efficacy of RT alone in the treatment of head and neck ACC. They started by saying that "comparison of the efficacy of RT alone with that of surgery and RT is hampered by selection bias; patients with early-stage lesions that are resectable tend to undergo surgery, whereas those with advanced, unresectable cancers tend to be treated with RT alone. The 10-year outcomes after RT vs surgery and RT were as follows: local control, $43 \%$ vs $91 \%$; absolute survival, $42 \%$ vs 55\%; and cause-specific survival, $48 \%$ vs $71 \%$ " 57 .

In 1987, Catterall et al. ${ }^{67}$ first presented a series of 65 advanced or recurrent salivary glands tumour treated by fast neutron radiotherapy. Local control and 5-year survival rates were $72 \%$ and $50 \%$, respectively. After then, some other studies on neutron radiotherapy for head and neck ACC have been published. The results were encouraging in almost all the patients. However, a study presenting a large series of 84 patients with ACCs of minor salivary glands reported that: "Patients without involvement of the cavernous sinus, base of skull, or nasopharynx (51 patients) had a 5 -year actuarial local-regional control rate of 59\%, whereas local-regional control was significantly lower (15\%) for patients with tumours involving these sites" ${ }^{68}$. A following paper presented a very large series of patients with salivary glands neoplasms treated with curative intent using fast neutron radiotherapy after previous surgical resection. Of the 279 cases of the series (ACCs 68\%), 263 had evidence of gross residual disease, 141 and 138 had tumours of the major and minor salivary glands, respectively. Patients without skull base invasion had a statistically significant improvement in cause-specific survival ${ }^{69}$. Two studies compared neutron to conventional photon and/or electron radiotherapy for the treatment of advanced salivary gland tumors ${ }^{70}$ and, in particular, salivary glands ACC ${ }^{71}$. Both studies demonstrated a statistically significant difference in the local-regional control (56\% vs 17\%, and $75 \%$ vs $32 \%$ ), although no improvement in survival was seen. Most studies did not report the rates of late complications of neutron radiotherapy. A study on 140 cases found that posttreatment trismus occurred in 56\%, acute mucositis and xerostomia occurred in approximately $88 \%$ and $89 \%$ of patients, respectively, and osteoradionecrosis was reported in $5.7 \%$ of patients ${ }^{72}$. In the version 2.2019 of the NCCN guidelines for head and neck tumours ${ }^{7}$, there is the following statement: "Results from a retrospective cohort study including 545 patients with salivary gland tumours treated 
between 1997 and 2010 showed better local control and survival outcomes with neutron therapy, relative to photon therapy ${ }^{73}$. However, risk of late effects with neutron therapy is high and tends to increase over time, with estimates as high as $20 \%$ at 9 years. The panel no longer recommends neutron therapy as a general solution for salivary glands cancers due to the diminishing demand, concerns regarding methodologic robustness of randomised trial data, and closure of all but one center in the United States" 7.

The second heavy particle therapy is proton radiotherapy.

\section{Treatment}

Surgery

- Wherever the primary tumour is located, the most common treatment for ACC is complete surgical resection \pm postoperative radiotherapy (PORT).

- Owing to the complex branching and connections of the facial nerve within the parotid, also a quite small ACC of the superficial lobe of the gland can often approach or come into contact with a branch of the nerve. Therefore, the radical resection of a parotid tumour according to the usual rules (free margins $\geq 5 \mathrm{~mm}$ ) is often impossible without the sacrifice of some branches of the nerve. Microscopic positive or close margins were between $40 \%$ and $70 \%$ in some important studies reporting these data.

- In the light of the often uncertain radicality, the debate between superficial or total parotidectomy is rather pointless because one must wonder which improvement of radicality may give the resection of few uninvolved glandular acini of the deep lobe after having dissected with difficulty the tumour from some branches of the facial nerve.

- For the submandibular gland the limit of radicality may be the lingual nerve and, in the paranasal sinuses, the extension of the tumour to the skull base and along the II branch of the trigeminal nerve.

- The surgical approach for the resection of an ACC of the oral cavity depends on the subsite of the tumour. The resection of a tumour of the hard palate may require a subtotal or total maxillectomy. For rare small tumours of the base of the tongue it may be possible a transoral resection or, nowadays, a transoral robotic resection. On the contrary, a pull-through or a mandibulotomy approach is required for large tumours involving both the base and the mobile tongue. In these cases a reconstruction with pedicled or microvascular free flaps is mandatory.

- The surgical treatment of the neck is indicated when there is clinical evidence of regional metastasis or when the resection of the primary tumour implies a trans-cervical approach. On the contrary, the management of cN0 neck remains controversial, mainly for malignancies of the parotid gland.

- The resection of the frequent lung metastases should be considered as a therapeutic option to achieve local control of disease when 2 conditions are met: (a) complete surgical resection is feasible and (b) the time to pulmonary relapse after primary tumour treatment is greater than 36 months.

\section{Radiotherapy}

- PORT is almost always used for ACC, mainly for patients with T3-4 tumours, incomplete or close resection, bone invasion, perineural invasion, and $\mathrm{pN}+$. However, two studies using national population-based data demonstrated that PORT does not significantly affect patient survival outcomes.

- Radiotherapy alone is generally used for patients with advanced, unresectable tumours, with low rates of local control.

- Two studies demonstrated an improvement in the local-regional control using fast neutrons or protons in comparison with conventional photon and/or electron radiotherapy. However, risk of late effects with neutron therapy is high and tends to increase over time.

- The most recent heavy particle therapy is carbon ion radiotherapy (CIRT), that demonstrated to be a good option for unresectable or uncompleted resected ACC.

\section{Chemotherapy and targeted therapy}

- A review of 114 publications on chemotherapy and targeted therapy concluded that the reported response rates were low and response duration generally short lived. 
The first proton beam accelerator used for therapeutic service was that of Loma Linda University (1990). Proton radiotherapy has demonstrated a good local control of the disease and a better toxicity profile compared to neutrons. However, the series of patients treated with protons are smaller than those with neutron, and present almost only ACC involving the skull base and lacrimal gland ${ }^{74-76}$. Bhattasali et al. ${ }^{77}$ presented a small series of 9 patients with unresectable head and neck ACC receiving definitive proton RT and concurrent cisplatin, and concluded that this treatment is a good options for these patients.

The last heavy particle therapy is carbon ion radiotherapy (CIRT). The first centre offering CIRT has been open in 1994 in Chiba (Japan). Among several types of ion species, carbon ions were chosen for cancer therapy because they were judged to have the most optimal properties in terms of superior physical and biological characteristics ${ }^{78}$. As of March 2010, 5,196 patients have been treated at the Chiba centre. Nowadays, CIRT has become a well-known noninvasive local treatment for solid cancer. Unfortunately, few other centres offering carbon ion radiotherapy have been opened in the world, among which there is the CNAO in Pavia (Italy). By pathological type, CIRT is effective against non-squamous cell types of tumours for which photon beams are minimally effective, including adenocarcinoma, ACC, hepatocellular carcinoma, malignant melanoma, bone, and soft-tissue tumors ${ }^{78}$. CIRT is also a good option for retreatment of inoperable recurrent salivary gland tumours with acceptable rates of acute and late toxicity ${ }^{79}$.

\section{Chemotherapy and targeted therapy}

In a review on the reported efficacy of various chemotherapy regimens and molecular therapies on recurrent/metastatic salivary gland ACC, Dodd and Slevin ${ }^{80}$ examined 114 publications on chemotherapy and possible molecular targets of therapy, including KIT, epidermal growth factor receptor (EGFR), human epidermal growth receptor-2 (HER-2), oestrogen and progesterone receptors, proliferating cell nuclear antigen (PCNA), Ki-67 and the p53, bcl-2 and SOX-4 genes. The conclusions of the authors were that the reported response rates to combination chemotherapy were low and response duration generally short lived. Moreover, no standard chemotherapy regimen could be recommended. However, Andry et al. ${ }^{81}$ reported that for recurrent and/or metastatic cancer, polychemotherapy (cisplatin based) gives a $25 \%$ response rate in ACC and should be used when the disease is overtly in progression. The response to targeted therapies with anti-EGF (epidermal growth factor) receptor molecules, antiangiogenic agents and tyrosine kinase inhibitors is also low.

\section{Prognostic factors and outcomes}

Because of the relative rarity of ACC, it is highly unlikely that the various prognostic factors and treatment options could be compared in a clinical trial. Moreover, it is difficult to learn indisputable data on outcomes from the literature because many studies report DFS and OS only at 5 years, that is a too short follow-up. It is well known that the natural history of ACC is characterised by an indolent growth rate and a high likelihood of hematogenous late dissemination. In the series presented by Mendenhall et al. ${ }^{57}$, the cumulative percentage of recurrences observed at various points in time after treatment were: 5 years, $73 \% ; 10$ years, 91\%; 15 years, 96\%; 20 years, $98 \%$; and 25 years, $100 \%$. Eneroth et al. ${ }^{82}$, in a historical study, reported the following rates of determinate survival for parotid ACC: 5 years, 73\%; 10 years, 39\%; 15 years, 21\%; and 20 years, $13 \%$. In the more recent study by Ellington et al. ${ }^{62}$ the overall 5-year, 10-year, and 15-year survival estimates for all stages were $90.34 \%, 79.88 \%$, and $69.22 \%$, respectively. All historical and recent studies demonstrated that advanced stage is the worst prognostic factor. Spiro et al. ${ }^{83}$ found that the cumulative 10 -year OS was $75 \%, 43 \%$, and $15 \%$ for stage I, stage II, and stage III-IV patients, respectively. The disease specific survival at 10 years was as high as $94 \%$ in patients with stage I disease. In more recent years, Marcinow et al. ${ }^{84}$ and Mays et al. ${ }^{85}$ reported very similar results for ACC of both major and minor salivary glands ${ }^{84}$, and for ACC of the sinonasal cavity ${ }^{85}$.

The impact of histologic grade on prognosis is controversial. Many studies demonstrated a worse prognosis for cases with solid histological type in comparison with tubular type ${ }^{20,85-87}$, while other studies demonstrated just the opposite ${ }^{19,83}$. However, it is proper to specify that the 3 histologic component of ACC (cribriform, tubular, and solid) are often mixed in the tumour. In fact, Mays et al. ${ }^{85}$ found solid variant in $38 \%$ of their 160 cases, but only $10 \%$ of patients revealed predominantly solid type histology. Finally, Seethala ${ }^{88}$, wondering the usefulness of the grading, wrote: "While prognostically useful, it is unclear whether grading of ACC is useful in patient management. Regardless of grade, all ACCs are treated with surgery plus irradiation because locally they are aggressive and 'high risk'".

Perineural invasion (PNI) has turned out to be a bad prognostic factors in most studies ${ }^{8,84}$. Marcinow et al. ${ }^{84}$ identified PNI as a poor prognostic factor for DFS, but not for OS. They hypothesised that the lack of significant impact on OS in these patients may be secondary to the indolent nature of ACC with frequent recurrences but overall good long-term survival. Garden et al. ${ }^{8}$ found that PNI was an adverse prognostic factor only when a major (named) nerve 
was involved. Amit et al. ${ }^{89}$ reported that PNI by itself was not predictor of outcome, whereas intraneural evidence of cancer was independent histologic sign of poor survival. Few studies analysed the impact of involved margins in ACC of the head and neck, and, mainly, the impact of close margins. Almost all studies found positive margins to significantly worsen survival. However, many authors consider positive and close margins jointly in follow-up assessment. Moreover, which is the required width of normal tissue around the tumour for ACC? In head and neck squamous cell carcinoma (SCC), margins that are $<5 \mathrm{~mm}$ are defined as close. Some recent studies demonstrated that the commonly used cut-off of $5 \mathrm{~mm}$ for a close margin lacks an evidential basis in predicting local recurrence for head and neck SCC, and that local recurrence-free survival was significantly affected only with surgical margins $\leq 2.2 \mathrm{~mm}$ in patients with oral tongue SCC ${ }^{90,91}$. Hence, it is correct to take the parameter of $5 \mathrm{~mm}$ for ACC? To the best of my knowledge, only two studies analysed specifically the impact of close margins in ACC of the head and neck. In a series of 198 patients, Garden et al. ${ }^{8}$ found that $18 \%$ of patients with positive margins developed local recurrences, compared to $9 \%$ of patients with close or uncertain margins, and $5 \%$ of those with negative margins $(p=0.02)$. In an International collaborative study of 507 patients, Amit et al. ${ }^{92}$ demonstrated that positive margins are associated with the worst outcome, whereas negative and close margins are associated with improved outcome, regardless of the distance from the tumour. The presence of close margin status resulted in similar outcome as negative margins for ACC of all sites examined except the oral cavity.

The primary site of ACC has been reported as a prognostic factor by most previous studies, with minor salivary gland tumours having a worse prognosis when compared to major salivary gland tumours. However, among minor gland ACCs, some studies found significantly worse survival in tumours originating in the sinonasal cavity in comparison with those originating in any other area of the head and neck, like the oral cavity ${ }^{8,85,92,93}$. There is a plausible explanation for this difference. A radical resection of a tumour of the paranasal sinuses is often limited by the proximity to skull base, restricting the limit of resection ${ }^{22,92}$. As proof of this surgical difficulties, Mays et al. demonstrated that those patients with tumour epicentre in a sinus had worse OS than other subsites of epicentre on both univariate analysis and multivariate analysis ${ }^{85}$. ACCs of the breast and skin have favourable prognosis with excellent survival ${ }^{93}$, unlike those of the tracheobronchial tree ${ }^{94}$.

The "surgeon" and "hospital" factors have not been taken into account in most studies. The resection of a large ACC is a difficult challenge, especially in the paranasal sinuses.
Eskander et al. ${ }^{95}$ analysed 17 studies examining a volumeoutcome relationship in the treatment of patients with head and neck cancer with meta-analysis for long-term survival results, and found that high-volume hospitals and high-volume surgeons have better overall survival than low-volume hospitals and surgeons, respectively. These data support the concept of centralisation of complex surgical procedures at centres able to meet minimum volume thresholds to improve patient outcomes. Ciccolallo et al. ${ }^{94}$ found that 10-year survival in Eastern Europe (56\%) was lower than in Northern Europe (69\%) and hypothesised that "multidisciplinary specialist care is well developed in much of Northern and Western Europe, whilst in some Eastern European countries cancer services are often provided by unspecialised professionals and access to imaging (CT, MRI) or enrolment in clinical trials may be limited".

The initial presence or later development of neck metastases is generally considered to be an unfavourable prognostic factor for head and neck squamous cell carcinomas, and also for ACCs ${ }^{84,94,96}$. The presence of subclinical or clinical nodal metastases in ACCs, that rarely have a regional spread, is the effect of an intrinsic biological aggressiveness of the tumour, and may be a predictive factor for distant metastases.

Like all head and neck cancers, also for ACC older age and comorbidities significantly correlate with worse DFS and OS in most studies ${ }^{62,84,94}$. The impact of sex in the clinical outcome of head and neck ACC is controversial. The largest epidemiologic studies seem to suggest that women have better prognosis compared with men ${ }^{62,94}$. According Ellington et al.: "The sex-specific survival differences raise the possibility that hormonal influences may be at play. In addition, it is plausible that women could be more apt to adhere to the treatment plan or tolerate the treatment" 62 . However, in another study, female sex was a prognostic factor for higher rate of ACC recurrence ${ }^{84}$. The study by Ellington et al. also revealed a better prognosis among married individuals compared with a combined group that included never married, widowed, divorced, and separated patients ${ }^{62}$. The association between marital status and outcome is a previously described phenomenon reported across several cancer sites.

As previously discussed, ACC is an indolent but aggressive tumour with a high incidence of DM. In fact, about $10-15 \%$ of patients have DM at presentation ${ }^{62}$ and distant metastatic spread will occur in approximately half of the patients ${ }^{97}$. Sung et al. ${ }^{98}$ found that DM occurred in $48 \%$ of patients and developed more frequently in patients with tumours of the solid histologic subtype than in patients with tubular or cribriform subtypes. Moreover, DM occurred less frequently in the minor salivary glands of the sinona- 


\section{Prognostic factors and outcomes}

- Because of the relative rarity of ACC, it is highly unlikely that the various prognostic factors and treatment options could be compared in a clinical trial. Moreover, many studies report the overall survival only at 5 years, which is too short. In a recent study on ACC of the head and neck, the overall 5-year, 10-year, and 15-year survival estimates for all stages were $90.34 \%, 79.88 \%$, and $69.22 \%$, respectively.

- The advanced stage, the perineural and intraneural invasion, the primary site, involved margins, and the initial presence or later development of neck metastases have been reported to be bad prognostic factors by most studies. The impact of histologic grade on prognosis is controversial.

sal tract than in major salivary glands or in other minor salivary glands, and development of DM was not affected by tumour stage. Median survival times after appearance of DM among patients with isolated lung metastases and those with bone metastases with or without lung involvement were 54 and 21 months, respectively. The rate of late DM was even higher in the series presented by van der Wal et al. (54.9\%) ${ }^{52}$. The average time between the occurrence of lung metastases and death was 32.3 months and between the occurrence of metastases elsewhere and death 20.6 months. Spiro ${ }^{53}$ found that large tumour size and lymph node involvement were predictive of DM, and that 74/196 patients had DM (38\%), 51 of whom had also a locoregional recurrence. Mendenhall et al. ${ }^{57}$ found that the 5 -year rate of distant metastases-free survival was $61 \%$ for patients with clinical perineural invasion compared with $82 \%$ for patients with incidental nerve invasion and $92 \%$ with no clinical or pathologic evidence of nerve invasion before treatment.

\section{Conclusions}

ACC is an uncommon tumour predominantly observed in the major and minor salivary glands. It may also arise in secretory glands located in other tissues, such as in the tracheobronchial tree, esophagus, breast, lungs, prostate, uterine cervix, Bartholin's glands, and skin. It is characterised by having an indolent but aggressive clinical course, the presence of early perineural invasion, frequent local recurrence, a relatively low probability of regional lymph node metastases, and a high rate of delayed distant metastases. Wherever the primary tumour is located, the most common treatment for ACC is complete surgical resection, with or without PORT, while RT alone and chemotherapy are commonly used in unresectable, or metastatic disease. Owing to the long natural history of ACC, the follow-up for patients must be at least 10 years long.

\section{References}

1 Arpino G, Clark GM, Mohsin S, et al. Adenoid cystic carcinoma of the breast: molecular markers, treatment, and clinical outcome. Cancer 2002;94:2119-2127. https://doi.org/10.1002/cncr.10455

2 Millar BA, Kerba M, Youngson B, et al. The potential role of breast conservation surgery and adjuvant breast radiation for adenoid cystic carcinoma of the breast. Breast Cancer Res Treat 2004;87:225-232. https://doi.org/10.1007/s10549-004-8693-z

3 Maziak DE. Biology of adenoid cystic carcinoma of the tracheobronchial tree and principles of management. Thorac Surg Clin 2018;28:145-148. https://doi.org/10.1016/j.thorsurg.2018.01.002

4 Ning Y, He W, Bian D, et al. Tracheo-bronchial adenoid cystic carcinoma: A retrospective study. Asia Pac J Clin Oncol 2019;15:244-249. https://doi.org/10.1111/ajco.13162

5 Naylor E, Sarkar P, Perlis CS, et al. Primary cutaneous adenoid cystic carcinoma. J Am Acad Dermatol 2008;58:636-641. https://doi. org/10.1016/j.jaad.2007.12.005

6 Woida FM, Ribeiro-Silva A. Adenoid cystic carcinoma of the Bartholin gland: an overview. Arch Pathol Lab Med 2007;131:796-798. https://doi.org/10.1043/1543-2165(2007)131[796:ACCOTB]2.0.CO;2

7 National Comprehensive Cancer Network. Head and Neck Cancers (Version 2.2019). http://www.nccn.org/professionals/physician_gls/ pdf/bone.pdf. Accessed April 10, 2019.

8 Garden AS, Weber RS, Morrison WH, et al. The influence of positive margins and nerve invasion in adenoid cystic carcinoma of the head and neck treated with surgery and radiation. Int J Radiat Oncol Biol Phys 1995;32:619-626. https://doi.org/10.1016/0360-3016(95)00122-F.

9 Erovic BM, Shah MD, Bruch G, et al. Outcome analysis of 215 patients with parotid gland tumors: a retrospective cohort analysis. J Otolaryngol Head Neck Surg 2015;44:43. https://doi.org/10.1186/ s40463-015-0097-z

10 Lee SY, Kim BH, Choi EC. Nineteen-year oncologic outcomes and the benefit of elective neck dissection in salivary gland adenoid cystic carcinoma. Head Neck 2014;36:1796-1801. https://doi.org/0.1002/ hed. 23537

11 Alajmo E, Polli G, De Meester W. Total parotidectomy - a routine treatment for parotid gland swellings? J Laryngol Otol 1989;103:181186. https://doi.org/10.1017/s0022215100108394

12 Casler JD, Conley JJ. Surgical management of adenoid cystic carcinoma in the parotid gland. Otolaryngol Head Neck Surg 1992;106:332338. https://doi.org/10.1177/019459989210600403

13 Fiorella R, Di Nicola V, Fiorella ML, et al. Major salivary gland diseases. Multicentre study. Acta Otorhinolaryngol Ital 2005;25:182190. Erratum in: Acta Otorhinolaryngol Ital 2005;25:337.

14 Boahene DK, Olsen KD, Lewis JE, et al. Mucoepidermoid carcinoma of the parotid gland: the Mayo clinic experience. Arch Oto- 
laryngol Head Neck Surg 2004;130:849-856. https://doi.org/10.1001/ archotol.130.7.849

15 Sood S, McGurk M, Vaz F. Management of salivary gland tumours: United Kingdom national multidisciplinary guidelines. J Laryngol Otol 2016;130(S2):S142-S149. https://doi.org/0.1017/ S0022215116000566

16 Gaillard C, Périé S, Susini B, et al. Facial nerve dysfunction after parotidectomy: the role of local factors. Laryngoscope 2005;115:287291. https://doi.org/10.1097/01.mlg.0000154735.61775.cd

17 Allen MS Jr, Marsh WL Jr. Lymph node involvement by direct extension in adenoid cystic carcinoma. Absence of classic embolic lymph node metastasis. Cancer 1976;38:2017-2021. https://doi.org/10.1002/10970142(197611)38:5<2017::aid-cncr2820380525>3.0.co;2-o

18 Bosch A, Brandenburg JH, Gilchrist KW. Lymph node metastases in adenoid cystic carcinoma of the submaxillary gland. Cancer 1980;45:2872-2877. https://doi.org/10.1002/10970142(19800601)45:11<2872::aid-cncr2820451125>3.0.co;2-0

19 Batsakis JG. Tumors of the head and neck. Clinical and pathological considerations. Second Edition. Baltimore: Williams \& Wilkins; 1979.

20 Michel G, Joubert M, Delemazure AS, et al. Adenoid cystic carcinoma of the paranasal sinuses: retrospective series and review of the literature. Eur Ann Otorhinolaryngol Head Neck Dis 2013;130:257262. https://doi.org/10.1016/j.anorl.2012.09.010

${ }_{21}$ Miller ED, Blakaj DM, Swanson BJ, et al. Sinonasal adenoid cystic carcinoma: Treatment outcomes and association with human papillomavirus. Head Neck 2017;39:1405-1411. https://doi.org/10.1002/ hed. 24778

22 Cantù G, Solero CL, Riccio S, et al. Surgery for malignant maxillary tumors involving the middle cranial fossa. Skull Base 2010;20:55-60. https://doi.org/10.1055/s-0029-1234021

23 Chaudhry AP, Vickers RA, Gorlin RJ. Intraoral minor salivary gland tumors. An analysis of 1,414 cases. Oral Surg Oral Med Oral Pathol 1961;14:1194-1226. https://doi.org/10.1016/0030-4220(61)90209-2

24 Bianchi B, Copelli C, Cocchi R, et al. Adenoid cystic carcinoma of intraoral minor salivary glands. Oral Oncol 2008;44:1026-1031. https:// doi.org/10.1016/j.oraloncology.2008.01.005

25 Beckhardt RN, Weber RS, Zane R, et al. Minor salivary gland tumors of the palate: clinical and pathologic correlates of outcome. Laryngoscope 1995;105:1155-1160. https://doi. org/10.1288/00005537-199511000-00003

26 Dubal PM, Unsal AA, Chung SY, et al. Population-based trends in outcomes in adenoid cystic carcinoma of the oral cavity. Am J Otolaryngol 2016;37:398-406. https://doi.org/10.1016/j.amjoto.2016.06.001

27 Eneroth CM, Hamberger CA. Principles of treatment of different types of parotid tumors. Laryngoscope 1974;84:1732-1740. https:// doi.org/10.1288/00005537-197410000-00007

28 Spiro RH, Huvos AG, Strong EW. Cancer of the parotid gland. A clinicopathologic study of 288 primary cases. Am J Surg 1975;130:452459. https://doi.org/10.1016/0002-9610(75)90483-3

29 Ettl T, Gosau M, Brockhoff G, et al. Predictors of cervical lymph node metastasis in salivary gland cancer. Head Neck 2014;36:517-523. https://doi.org/0.1002/hed.23332

30 International Head and Neck Scientific Group. Cervical lymph node metastasis in adenoid cystic carcinoma of the major salivary glands. J Laryngol Otol 2017;131:96-105. https://doi.org/10.1017/ S0022215116009749

31 Xiao R, Sethi RKV, Feng AL, et al. The role of elective neck dissection in patients with adenoid cystic carcinoma of the head and neck. Laryngoscope 2019;129:2094-2104. https://doi.org/10.1002/ lary. 27814
32 Zbären P, Schüpbach J, Nuyens M, et al. Elective neck dissection versus observation in primary parotid carcinoma. Otolaryngol Head Neck Surg 2005;132:387-391. https://doi.org/10.1016/j. otohns.2004.09.029

33 Atallah S, Moya-Plana A, Malard O, et al. Should a neck dissection be performed on patients with $\mathrm{cN} 0$ adenoid cystic carcinoma? A REFCOR propensity score matching study. Eur J Cancer 2020;130:250258. https://doi.org/10.1016/j.ejca.2019.12.026

34 Ning C, Zhao T, Wang Z, et al. Cervical lymph node metastases in salivary gland adenoid cystic carcinoma: a systematic review and meta-analysis. Cancer Manag Res 2018;10:1677-1685. https://doi. org/0.2147/CMAR.S164677

35 Vander Poorten V, Hunt J, Bradley PJ, et al. Recent trends in the management of minor salivary gland carcinoma. Head Neck 2014;36:444455. https://doi.org/10.1002/hed.23249

36 Suárez C, Barnes L, Silver CE, et al. Cervical lymph node metastasis in adenoid cystic carcinoma of oral cavity and oropharynx: a collective international review. Auris Nasus Larynx 2016;43:477-484. https://doi.org/10.1016/j.anl.2016.02.013

37 Speksnijder CM, van der Bilt A, Slappendel M, et al. Neck and shoulder function in patients treated for oral malignancies: a 1-year prospective cohort study. Head Neck 2013;35:1303-1313. https://doi. org/0.1002/hed.23131

38 Wang K, Moon DH, Amdur RJ, et al. Shoulder symptoms and quality of life impact of limited neck dissection after de-intensified chemoradiotherapy: secondary analysis of two prospective trials. Head Neck 2019;41:1213-1219. https://doi.org/10.1002/hed.25535

39 Cappiello J, Piazza C, Giudice M, et al. Shoulder disability after different selective neck dissections (levels II-IV versus levels II-V): a comparative study. Laryngoscope 2005;115:259-263. https://doi. org/10.1097/01.mlg.0000154729.31281.da

40 Cordesmeyer R, Kauffmann P, Laskawi R, et al. The incidence of occult metastasis and the status of elective neck dissection in salivary adenoid cystic carcinoma: a single center study. Oral Surg Oral Med Oral Pathol Oral Radiol 2018;125:516-519. https://doi.org/10.1016/j. oooo.2018.01.013

${ }^{41}$ Luksic I, Suton P. Elective neck dissection in adenoid cystic carcinoma of head and neck: yes or no? A systematic review. Eur Arch Otorhinolaryngol 2019;276:2957-2962. https://doi.org/10.1007/ s00405-019-05669-1

42 Kelley DJ, Spiro RH. Management of the neck in parotid carcinoma. Am J Surg 1996;172:695-697. https://doi.org/0.1016/ s0002-9610(96)00307-8

43 Amit M, Binenbaum Y, Sharma K, et al. Incidence of cervical lymph node metastasis and its association with outcomes in patients with adenoid cystic carcinoma. An international collaborative study. Head Neck 2015;37:1032-1037. https://doi.org/10.1002/hed.23711

44 Amit M, Na'ara S, Sharma K, et al. Elective neck dissection in patients with head and neck adenoid cystic carcinoma: an international collaborative study. Ann Surg Oncol 2015;22:1353-1359. https://doi. org/0.1245/s10434-014-4106-7

45 Lim CM, Gilbert MR, Johnson JT, et al. Clinical significance of intraparotid lymph node metastasis in primary parotid cancer. Head Neck 2014;36:1634-1637. https://doi.org/10.1002/hed.23507

46 Guntinas-Lichius O, Thielker J, Robbins KT, et al. Prognostic role of intraparotid lymph node metastasis in primary parotid cancer: systematic review. Head Neck 2021;43:997-1008 https://doi.org/10.1002/ hed.26541

47 Chisholm EJ, Elmiyeh B, Dwivedi RC, et al. Anatomic distribution of cervical lymph node spread in parotid carcinoma. Head Neck 2011;33:513-515. https://doi.org/10.1002/hed.21479 
48 Armstrong JG, Harrison LB, Thaler HT. The indications for elective treatment of the neck in cancer of the major salivary glands. Cancer 1992;69:615-619. https://doi.org/10.1002/1097-0142(19920201)et al69:3<615::aid-cncr2820690303>3.0.co;2-9

49 Klussmann JP, Ponert T, Mueller RP, et al. Patterns of lymph node spread and its influence on outcome in resectable parotid cancer. Eur J Surg Oncol 2008;34:932-937. https://doi.org/10.1016/j. ejso.2008.02.004

50 Gao M, Hao Y, Huang MX, et al. Clinicopathological study of distant metastases of salivary adenoid cystic carcinoma. Int J Oral Maxillofac Surg 2013;42:923-928. https://doi.org/10.1016/j.ijom.2013.04.006

51 Ko YH, Lee MA, Hong YS, et al. Prognostic factors affecting the clinical outcome of adenoid cystic carcinoma of the head and neck. Jpn J Clin Oncol 2007;37:805-811. https://doi.org/10.1093/jjco/hym119

52 van der Wal JE, Becking AG, Snow GB, et al. Distant metastases of adenoid cystic carcinoma of the salivary glands and the value of diagnostic examinations during follow-up. Head Neck 2002;24:779-783. https://doi.org/10.1002/hed.10126

53 Spiro RH. Distant metastasis in adenoid cystic carcinoma of salivary origin. Am J Surg 1997;174:495-498. https://doi.org/0.1016/ s0002-9610(97)00153-0

54 Locati LD, Guzzo M, Bossi P, et al. Lung metastasectomy in adenoid cystic carcinoma (ACC) of salivary gland. Oral Oncol 2005;41:890894. https://doi.org/10.1016/j.oraloncology.2005.04.014

55 Girelli L, Locati L, Galeone C, et al. Lung metastasectomy in adenoid cystic cancer: Is it worth it? Oral Oncol 2017;65:114-118. https://doi. org/10.1016/j.oraloncology.2016.10.018

56 Osborn DA. Morphology and the natural history of cribriform adenocarcinoma (adenoid cystic carcinoma). J Clin Pathol 1977;30:195205. https://doi.org/0.1136/jcp.30.3.195

57 Mendenhall WM, Morris CG, Amdur RJ, et al. Radiotherapy alone or combined with surgery for adenoid cystic carcinoma of the head and neck. Head Neck 2004;26:154-162. https://doi.org/10.1002/ hed. 10380

58 Terhaard $\mathrm{CH}$, Lubsen $\mathrm{H}$, Rasch $\mathrm{CR}$, et al. The role of radiotherapy in the treatment of malignant salivary gland tumors. Int $\mathrm{J} \mathrm{Ra-}$ diat Oncol Biol Phys 2005;61:103-111. https://doi.org/10.1016/j. ijrobp.2004.03.018

59 Mahmood U, Koshy M, Goloubeva O, et al. Adjuvant radiation therapy for high-grade and/or locally advanced major salivary gland tumors. Arch Otolaryngol Head Neck Surg 2011;137:1025-1030. https://doi.org/10.1001/archoto.2011.158

60 Safdieh J, Givi B, Osborn V, et al. Impact of adjuvant radiotherapy for malignant salivary gland tumors. Otolaryngol Head Neck Surg 2017;157:988-994. https://doi.org/10.1177/0194599817717661

61 Lee A, Givi B, Osborn VW, et al. Patterns of care and survival of adjuvant radiation for major salivary adenoid cystic carcinoma. Laryngoscope 2017;127:2057-2062. https://doi.org/0.1002/lary.26516

62 Ellington CL, Goodman M, Kono SA, et al. Adenoid cystic carcinoma of the head and neck: Incidence and survival trends based on 1973-2007 surveillance, epidemiology, and end results data. Cancer 2012;118:4444-4451. https://doi.org/10.1002/cncr.27408

63 Lloyd S, Yu JB, Wilson LD, et al. Determinants and patterns of survival in adenoid cystic carcinoma of the head and neck, including an analysis of adjuvant radiation therapy. Am J Clin Oncol 2011;34:7681. https://doi.org/0.1097/COC.0b013e3181d26d45

64 Mantravadi AV, Moore MG, Rassekh CH. AHNS series: do you know your guidelines? Diagnosis and management of salivary gland tumors. Head Neck 2019;41:269-280. https://doi.org/10.1002/hed.25499

65 Frankenthaler RA, Byers RM, Luna MA, et al. Predicting occult lymph node metastasis in parotid cancer. Arch Otolaryn- gol Head Neck Surg 1993;119:517-520. https://doi.org/10.1001/ archotol.1993.01880170041008

66 Balamucki CJ, Amdur RJ, Werning JW, et al. Adenoid cystic carcinoma of the head and neck. Am J Otolaryngol 2012;33:510-518. https:// doi.org/10.1016/j.amjoto.2011.11.006

67 Catterall M, Errington RD. The implications of improved treatment of malignant salivary gland tumors by fast neutron radiotherapy. Int J Radiat Oncol Biol Phys 1987;13:1313-1318. https://doi. org/0.1016/0360-3016(87)90222-7

68 Douglas JG, Laramore GE, Austin-Seymour M, et al. Neutron radiotherapy for adenoid cystic carcinoma of minor salivary glands. Int J Radiat Oncol Biol Phys 1996;36:87-93. https://doi.org/10.1016/ s0360-3016(96)00213-1

69 Douglas JG, Koh WJ, Austin-Seymour M, et al. Treatment of salivary gland neoplasms with fast neutron radiotherapy. Arch Otolaryngol Head Neck Surg 2003;129:944-948. https://doi.org/10.1001/ archotol.129.9.944

70 Lindsley KL, Cho P, Stelzer KJ, et al. Clinical trials of neutron radiotherapy in the United States. Bull Cancer Radiother 1996;83 Suppl:78s-86s. https://doi.org/10.1016/0924-4212(96)84889-4

71 Huber PE, Debus J, Latz D, et al. Radiotherapy for advanced adenoid cystic carcinoma: neutrons, photons or mixed beam? Radiother Oncol 2001;59:161-167. https://doi.org/10.1016/s0167-8140(00)00273-5

72 Davis C, Sikes J, Namaranian P, et al. Neutron beam radiation therapy: an overview of treatment and oral complications when treating salivary gland malignancies. J Oral Maxillofac Surg 2016;74:830835. https://doi.org/10.1016/j.joms.2015.10.014

73 Timoshchuk MA, Dekker P, Hippe DS, et al. The efficacy of neutron radiation therapy in treating salivary gland malignancies. Oral Oncol 2019;88:51-57. https://doi.org/10.1016/j.oraloncology.2018.11.006

74 Pommier P, Liebsch NJ, Deschler DG, et al. Proton beam radiation therapy for skull base adenoid cystic carcinoma. Arch Otolaryngol Head Neck Surg 2006;132:1242-1249. https://doi.org/0.1001/ archotol.132.11.1242

75 Linton OR, Moore MG, Brigance JS, et al. Proton therapy for head and neck adenoid cystic carcinoma: initial clinical outcomes. Head Neck 2015;37:117-124. https://doi.org/10.1002/hed.23573

76 Wolkow N, Jakobiec FA, Lee H, et al. Long-term outcomes of globepreserving surgery with proton beam radiation for adenoid cystic carcinoma of the lacrimal gland. Am J Ophthalmol 2018;195:43-62. https://doi.org/10.1016/j.ajo.2018.07.024

77 Bhattasali O, Holliday E, Kies MS, et al. Definitive proton radiation therapy and concurrent cisplatin for unresectable head and neck adenoid cystic carcinoma: a series of 9 cases and a critical review of the literature. Head Neck 2016;38(Suppl 1):E1472-1480. https://doi. org/10.1002/hed.24262

78 Okada T, Kamada T, Tsuji H, et al. Carbon ion radiotherapy: clinical experiences at National Institute of Radiological Science (NIRS). J Radiat Res 2010;51:355-364. https://doi.org/10.1269/jrr.10016

79 Vischioni B, Dhanireddy B, Severo C, et al. Reirradiation of salivary gland tumors with carbon ion radiotherapy at CNAO. Radiother Oncol 2020;145:172-177. https://doi.org/10.1016/j.radonc.2020.01.004

80 Dodd RL, Slevin NJ. Salivary gland adenoid cystic carcinoma: a review of chemotherapy and molecular therapies. Oral Oncol 2006;42:759769. https://doi.org/10.1016/j.oraloncology.2006.01.001

81 Andry G, Hamoir M, Locati LD, et al. Management of salivary gland tumors. Expert Rev Anticancer Ther 2012;12:1161-1168. https://doi. org/10.1586/era.12.92

82 Eneroth CM, Hjertman L, Moberger G. Adenoid cystic carcinoma of the palate. Acta Otolaryngol 1968;66:248-260. https://doi. org/10.3109/00016486809126292 
83 Spiro RH, Huvos AG. Stage means more than grade in adenoid cystic carcinoma. Am J Surg 1992;164:623-628. https://doi.org/10.1016/ s0002-9610(05)80721-4

${ }_{84}$ Marcinow A, Ozer E, Teknos T, et al. Clinicopathologic predictors of recurrence and overall survival in adenoid cystic carcinoma of the head and neck: a single institutional experience at a tertiary care center. Head Neck 2014;36:1705-1711. https://doi.org/10.1002/ hed. 23523

85 Mays AC, Hanna EY, Ferrarotto R, et al. Prognostic factors and survival in adenoid cystic carcinoma of the sinonasal cavity. Head Neck 2018;40:2596-2605. https://doi.org/10.1002/hed.25335

86 da Cruz Perez DE, de Abreu Alves F, Nobuko Nishimoto I, et al. Prognostic factors in head and neck adenoid cystic carcinoma. Oral Oncol 2006;42:139-146. https://doi.org/10.1016/j.oraloncology.2005.06.024

87 Eneroth CM, Hjertman L, Moberger G. Malignant tumours of the submandibular gland. Acta Otolaryngol 1967;64:514-536. https://doi. org/10.3109/00016486709139137

88 Seethala RR. An update on grading of salivary gland carcinomas. Head Neck Pathol 2009;3:69-77. https://doi.org/10.1007/ s12105-009-0102-9

89 Amit M, Binenbaum Y, Trejo-Leider L, et al. International collaborative validation of intraneural invasion as a prognostic marker in adenoid cystic carcinoma of the head and neck. Head Neck 2015;37:10381045. https://doi.org/10.1002/hed.23710

90 Zanoni DK, Migliacci JC, Xu B, et al. A proposal to redefine close surgical margins in squamous cell carcinoma of the oral tongue. JAMA Otolaryngol Head Neck Surg 2017;143:555-560. https://doi. org/10.1001/jamaoto.2016.4238

91 Tasche KK, Buchakjian MR, Pagedar NA, et al. Definition of "Close margin" in oral cancer surgery and association of margin distance with local recurrence rate. JAMA Otolaryngol Head Neck Surg 2017;143:1166-1172. https://doi.org/10.1001/jamaoto.2017.0548

92 Amit M, Na'ara S, Trejo-Leider L, et al. Defining the surgical margins of adenoid cystic carcinoma and their impact on outcome: an international collaborative study. Head Neck 2017;39:1008-1014. https://doi. org/10.1002/hed.24740

$93 \mathrm{Li} \mathrm{N}, \mathrm{Xu} \mathrm{L}$, Zhao H, et al. A comparison of the demographics, clinical features, and survival of patients with adenoid cystic carcinoma of major and minor salivary glands versus less common sites within the Surveillance, Epidemiology, and End Results registry. Cancer 2012;118:3945-3953. https://doi.org/10.1002/cncr.26740

94 Ciccolallo L, Licitra L, Cantú G, et al.; EUROCARE Working Group. Survival from salivary glands adenoid cystic carcinoma in European populations. Oral Oncol 2009;45:669-674. https://doi.org/10.1016/j. oraloncology.2008.10.010

95 Eskander A, Merdad M, Irish JC, et al. Volume-outcome associations in head and neck cancer treatment: a systematic review and metaanalysis. Head Neck 2014;36:1820-1834. https://doi.org/10.1002/ hed. 23498

96 Cantù G, Bimbi G, Miceli R, et al. Lymph node metastases in malignant tumors of the paranasal sinuses: prognostic value and treatment. Arch Otolaryngol Head Neck Surg 2008;134:170-177. https://doi. org/10.1001/archoto.2007.30

97 Dillon PM, Chakraborty S, Moskaluk CA, et al. Adenoid cystic carcinoma: A review of recent advances, molecular targets, and clinical trials. Head Neck 2016;38:620-627. https://doi.org/10.1002/hed.23925

98 Sung MW, Kim KH, Kim JW, et al. Clinicopathologic predictors and impact of distant metastasis from adenoid cystic carcinoma of the head and neck. Arch Otolaryngol Head Neck Surg 2003;129:11931197. https://doi.org/10.1001/archotol.129.11.1193 